\title{
Repulsive Guidance Molecule (RGM) Gene Function Is Required for Neural Tube Closure But Not Retinal Topography in the Mouse Visual System
}

\author{
Vera Niederkofler, ${ }^{1 *}$ Rishard Salie, ${ }^{1 *}$ Markus Sigrist, ${ }^{1}$ and Silvia Arber ${ }^{1,2}$ \\ ${ }^{1}$ Biozentrum, Department of Cell Biology, University of Basel, 4056 Basel, Switzerland, and ${ }^{2}$ Friedrich Miescher Institute, 4058 Basel, Switzerland
}

\begin{abstract}
The establishment of topographic projections in the developing visual system depends on the spatially and temporally controlled expression of axon guidance molecules. In the developing chick tectum, the graded expression of the repulsive guidance molecule (RGM) has been proposed to be involved in controlling the topography of the retinal ganglion cell (RGC) axon termination zones along the anteroposterior axis of the tectum. We now show that there are three mouse proteins homologous to chick RGM displaying similar proteolytic processing but exhibiting differential cell-surface targeting by glycosyl phosphatidylinositol anchor addition. Two members of this gene family ( $m R G M a$ and $m R G M b$ ) are expressed in complementary patterns in the nervous system, and $m R G M a$ is expressed prominently in the superior colliculus at the time of anteroposterior targeting of RGC axons. The third member of the family $(m R G M c)$ is expressed almost exclusively in skeletal muscles. Functional studies in the mouse reveal a role for $m R G M a$ in controlling cephalic neural tube closure, thus defining an unexpected role for $m R G M a$ in early embryonic development. In contrast, $m R G M a$ mutant mice did not exhibit defects in anteroposterior targeting of RGC axons to their stereotypic termination zones in the superior colliculus.
\end{abstract}

Key words: RGM; retinal topography; exencephaly; neural tube closure; GPI; axon guidance

\section{Introduction}

The precise temporal and spatial interplay of different extracellular proteins is essential for the establishment of correct morphology and patterning of the nervous system at early developmental stages as well as for the assembly of neuronal circuits later in development. Many extracellular proteins have been studied for their role in controlling axon outgrowth to target regions in an attempt to address the question of how axonal projections of different neuronal populations achieve precise targeting to the region they innervate in the mature nervous system. These studies have led to the concept that extracellular guidance molecules can act in both attractive and repulsive manners (Tessier-Lavigne and Goodman, 1996) and much is known about the mechanisms by which these molecules direct axons toward their targets ( $\mathrm{Yu}$ and Bargmann, 2001; Dickson, 2002).

One system in which the underlying molecular mechanisms controlling the development of precise axonal projections has been studied extensively is the projection of retinal ganglion cells (RGCs) to either the chick tectum or the rodent superior colliculus (Sperry, 1963; McLaughlin et al., 2003). The anatomical ar-

\footnotetext{
Received Oct. 15, 2003; revised Nov. 19, 2003; accepted Nov. 21, 2003.

This work was supported by a grant from the Swiss National Science Foundation, by the Kanton of Basel-Stadt, and MigraGen. We thank Monika Mielich, Jean-Francois Spetz, Patrick Kopp, and Bernard Kuchemann for excellent technical assistance, Bernhard Mueller for support and valuable insights, Robert Hindges for expert advice on retinocollicular tracing experiments, and Thomas Jessell for discussions and helpful comments on this manuscript. *V.N. and R.S. contributed equally to this work.

Correspondence should be addressed to Dr. Silvia Arber, Biozentrum, Department of Cell Biology, University of Basel, Klingelbergstrasse 70, 4056 Basel, Switzerland. E-mail: silvia.arber@unibas.ch.

DOI:10.1523/JNEUROSCI.4610-03.2004

Copyright $\odot 2004$ Society for Neuroscience $\quad$ 0270-6474/04/240808-11\$15.00/0
}

rangement of retinocollicular projections during rodent development and in the mature system has been well defined (Simon and O'Leary, 1992). In the mature retinocollicular system there is a precise topography of projections from the retina to the superior colliculus: Temporal RGC axons consistently terminate in the anterior superior colliculus, whereas nasal RGC axons project to the posterior superior colliculus (Sperry, 1963; McLaughlin et al., 2003). This observation has led to the proposal that RGC axons terminating in the anterior superior colliculus may be repelled by molecular cues found at a higher concentration in the posterior relative to the anterior superior colliculus (Sperry, 1963). Consistent with this model, temporal RGCs are repelled by membranes isolated from the posterior chick tectum and grow preferentially on anterior tectal membranes (Walter et al., 1987). The isolation of molecules expressed in a low anterior to high posterior gradient in the chick tectum led to the discovery that members of the Ephrin family (in particular EphrinA2 and EphrinA5) possess such a repulsive activity (Drescher et al., 1995; Nakamoto et al., 1996; Monschau et al., 1997). Both EphrinA2 and EphrinA5 are expressed in a gradient in the chick tectum and the mouse superior colliculus (Drescher et al., 1995; Cheng et al., 1995; Feldheim et al., 2000). Functional evidence supports the idea that EphrinA2 and EphrinA5 act as repulsive guidance cues, confining the termination zones of temporal RGCs to more anterior positions (Nakamoto et al., 1996; Feldheim et al., 2000; McLaughlin et al., 2003).

Chick RGM (cRGM) has been reported to possess an in vitro activity similar to the Ephrins, causing growth cone collapse and preferential guidance of temporal RGC axons (Monnier et al., 2002). In contrast to Ephrins, however, the in vivo role of RGM 
remains unclear. To determine whether $R G M$ does indeed play a role in the establishment of retinocollicular projections in vivo we decided to isolate the corresponding mouse gene and examine the neural phenotype of mice lacking $R G M$ gene function.

We discovered three genes with homology to $c R G M$ within the mouse genome. All three murine members of this protein family (mRGMa, mRGMb, and mRGMc) show a C-terminal GPIanchor consensus sequence, but the efficiency of cell-surface transport of the different family members is highly variable. The expression of $m R G M a$ and $m R G M b$ is confined primarily to the nervous system, in which they are expressed in complementary patterns. In contrast, the most prominent expression of $m R G M c$ is found in skeletal muscles. Analysis of $m R G M a$ mutant mice demonstrated that the development of RGC projections from the retina to the colliculus and topographic mapping of these projections to defined anteroposterior positions within the superior colliculus was normal. In contrast, $\sim 50 \%$ of $m R G M a$ mutant mice showed defects in cephalic neural tube closure. Together, these findings identify a novel family of extracellular GPI anchored proteins in the mouse, with homology to cRGM, and reveal an unexpected role for $m R G M a$ in the process of neural tube closure.

\section{Materials and Methods}

Characterization of $m R G M$ gene family and histology. The three members of the $m R G M$ gene family were isolated by database searches [GenBank accession numbers AI118914 ( $m R G M a)$, BG519283 ( $m R G M b)$, and AA656608 $(m R G M c)$ ]. Signal peptide and GPI anchor cleavage sites were determined using the following programs [http://www.cbs.dtu.dk/ services/SignalP-2.0/\#submission (Nielsen et al., 1999) and http:// mendel.imp.univie.ac.at/gpi/gpi_server.html (Eisenhaber et al., 1999)]. Percentage identity of mRGM family members to cRGMa was determined using National Center for Biotechnology Information (Bethesda, MD) BlastP version 2.2.6. To determine $\mathrm{N}$-terminal proteolytic cleavage sites, $c R G M a$ (Monnier et al., 2002) and $m R G M s$ were cloned into pSecTag2A (Invitrogen, San Diego, CA) in frame with the His-tag (cRGMa, 93-1217 bp; $m R G M a, 91-1232$ bp; $m R G M b, 144-1243$ bp; $m R G M c, 94-1178$ bp). COS-7 cell (American Type Culture Collection, Manassas, VA) conditioned medium was collected 2-5 d after transfection, and proteins were purified over an Ni-nitrilotriacetic acid-column (Qiagen, Basel, Switzerland). N-terminal sequencing was performed by Edman degradation (Analytical Research and Services, University of Bern, Bern, Switzerland).

For in situ hybridization analysis, sections were hybridized with digoxigenin-labeled probes (Schaeren-Wiemers and Gerfin-Moser, 1993) directed against mouse $m R G M a, m R G M b, m R G M c, c R G M a$ (Monnier et al., 2002), mEphrinA5 (BG921710), mEphrinA2 (AA170896), and mPea3 (Livet et al., 2002). Antibodies used in this study were: rabbit anti-GAP-43 (Arber et al., 1999), rabbit anti-mRGMa (peptide antibody to amino acids 316-331), rabbit anti-mRGMb (peptide antibody to amino acids 256-270), rabbit anti-mRGMc (peptide antibody to amino acids 314-328), rabbit anti-cRGMa (peptide antibody to amino acids 319-332), mouse anti-bromodeoxyuridine (BrdU; Becton Dickinson, San Jose, CA), mouse anti-Myc (9E10; American Type Culture Collection), mouse anti-skeletal $\alpha$-actinin (Sigma, Buchs, Switzerland), goat anti- $\beta$-galactosidase (Arnel, New York, NY) and sheep antienhanced green fluorescent protein (eGFP; Biogenesis, Kingston, NH). Chick electroporations were performed as described previously (Briscoe et al., 2000). Cryostat sections were processed for immunohistochemistry as described previously (Arber et al., 1999), using fluorophoreconjugated secondary antibodies (1:1000; Molecular Probes, Eugene, OR).

Generation and analysis of $m R G M a$ mutant mice. A mouse genomic library was screened using an $m R G M a$-specific probe (Incyte Genomics, Palo Alto, CA). An EcoRV genomic fragment containing the exon coding for the $\mathrm{N}$-terminal methionine and signal peptide was replaced by a thymidine kinase (TK)-neomycin cassette using homologous recombination in embryonic stem (ES) cells (targeting frequency, 1:2000). ES cell recombinants were screened by genomic Southern blot (EcoRI digest; $3^{\prime}$ probe ( $\sim 200$ bp): oligonucleotides (A) 5'-TTGACCTGCCGCTGAGCACA-3' and (B) $5^{\prime}$-CTGGGCACTGAGTGGTAAGG-3') and verified by PCR (see Fig. 5 for position of oligonucleotides: [3], 5'-CATCCAACAAGGCTCCACTGGAAGG-3'; [4], 5'-TGCGAAGTGGACCTGGGACCGCG-3'). The identification of $m R G M a^{-1-}$ mice was performed by genomic Southern blotting and PCR (see Fig. 5 for position of oligonucleotides: [1], 5' CAGGTAGGCACAACTCCTTGGTGG-3'; [2], 5'-TTAGCACGTCTGAGCCTGTGTCCG-3'). Reverse transcription (RT)-PCR was performed according to the instructions of the manufacturer (Promega, Madison, WI) using postnatal day $0(\mathrm{P0})$ mouse brain total RNA and the following oligonucleotides: [5], 5'-CTTCCTTCTCTGCAGCTTCCCCGC-3'; [6], 5' CTGGCGCGCCAGCTTGGTAGACTTTCTGGTCC-3'. The lack of antibodies recognizing endogenous $\mathrm{mRGM}$ a prohibited us from confirming the absence of mRGMa protein in $m R G M a^{-1-}$ mice.

BrdU experiments were performed by the intraperitoneal injection of BrdU (50 $\mathrm{gg} / \mathrm{gm}$ body weight; Sigma, Buchs, Switzerland) $2 \mathrm{hr}$ before killing, and BrdU was detected as described previously (Arber et al., 1999). Terminal deoxynucleotidyl transferase-mediated biotinylated UTP nick end labeling (TUNEL) to detect apoptotic cells in wholemount embryos was performed as described by the manufacturer (Roche, Rotkreuz, Switzerland). Anterograde labeling of retinocollicular projections was done essentially as described previously (Simon and O'Leary, 1992). Briefly, 5\% DiI (Molecular Probes) in dimethyl formamide solution was injected into the retina at $\mathrm{P} 0$ or the nasal or temporal extreme of the retina at P9-P12 with a fine glass micropipette using a Picospritzer III (Parker, Fairfield, NJ). One day later for fills at P0 or $2 \mathrm{~d}$ later for focal injections, colliculi were analyzed blind to genotype with confocal microscopy (Olympus, Hamburg, Germany). The retinas were examined to verify a single injection point for focal injections.

\section{Results}

\section{Isolation of three genes in the mouse genome homologous to cRGM}

To isolate genes homologous to $c R G M$ (Monnier et al., 2002) in the mouse genome, we searched the database for mouse expressed sequence tags and genomic sequences with a high degree of identity to $c R G M$. We found that the mouse genome contains three genes with homology to $c R G M$ (in this paper, now referred to as $c R G M a)$. Mouse RGMa (mRGMa) is most closely related to cRGMa and shows an identity of $80 \%$ to cRGMa at the amino acid level (Fig. 1 $A$ ). The two more distantly related members of the RGM family of proteins, which we called mRGMb and mRGMc, show identities to cRGMa of 50 and $42 \%$, respectively (Fig. $1 A$ ). Additional evidence that $m R G M b$ may be more closely related to $m R G M a$ than $m R G M c$ comes from an analysis of the organization of the respective genomic loci. The positions of intron-exon junctions as well as the sizes of introns are highly conserved between $m R G M a$ (chromosome 7) and $m R G M b$ (chromosome 17; data not shown). In addition, two homologous genes [chromodomain helicase DNA binding protein 1 (CHD1) and chromodomain helicase DNA binding protein 2 (CHD2)] are located in close proximity to $m R G M b(m R G M b / C H D 1)$ and $m R G M a(m R G M a / C H D 2)$, respectively, suggesting that $m R G M a$ and $m R G M b$ may have evolved by gene duplication. In contrast, the genomic organization of $m R G M c$ is highly divergent to $m R G M a$ or $m R G M b$ (data not shown).

We found that like cRGMa, all three members of the mouse family of RGM proteins contain an N-terminal consensus signal peptide for targeting to the endoplasmic reticulum (Fig. $1 \mathrm{~A}$, gray box) and a C-terminal GPI anchor consensus sequence (Fig. $1 A$ ). However, the quality and score of the best site predicted for the addition of a GPI anchor varied significantly among the three mouse homologues of RGM and cRGMa (cRGMa, 7.93; mRGMa, 1.14; mRGMb, 2.72; mRGMc, 6.63), raising the possi- 
bility that not all members of the RGM family are processed with the same efficiency by the addition of a C-terminal GPI anchor. Because differential processing could affect the efficiency of protein targeting to the plasma membrane, in which GPI anchored proteins are usually localized to lipid rafts (Sharom and Lehto, 2002), we assessed the subcellular localization of cRGMa, mRGMa, mRGMb, and mRGMc by transfecting full-length RGMs and a cDNA encoding nuclear $\beta$-galactosidase from a bicistronic mRNA into COS-7 cells. To label cell-surface accumulated proteins, we incubated live transfected cells with primary antibodies specific to individual RGM family members before fixation and permeabilization of cells. For the identification of transfected cells, we stained them with an antibody to $\beta$-galactosidase after fixation and permeabilization. Although strong cellsurface labeling was detected on cells transfected with cRGMa and mRGMc, mRGMa-expressing cells appeared to be labeled somewhat less intensely, and very low if any staining was detected on the plasma membrane of cells transfected with mRGMb (Fig. 2A-D). When transfected cells were fixed and permeabilized before incubation with the primary antibody, all four RGMs displayed strong labeling (Fig. $2 E-H)$. However, mRGMb protein was highly concentrated in the perinuclear endoplasmic reticulum/Golgi compartment, consistent with the observation that mRGMb protein is not efficiently targeted to the cell surface (Fig. 2G). Consistent with these data, supernatant collected from COS-7 cells transfected with individual RGM cDNA constructs contained high levels of mRGMc or cRGMa protein but only very low levels of $\mathrm{mRGMb}$ protein (data not shown), indicating that cellsurface-exposed RGMs may also be processed and released into the extracellular medium. To determine whether the differential subcellular distribution was also found in neurons in vivo, we electroporated embryonic day 3 (E3) chick spinal cords with vectors expressing mRGMa, mRGMb, or mRGMc. Whereas mRGMa and mRGMc proteins were expressed and efficiently transported into neuronal processes by E5, mRGMb appeared to be concentrated predominantly in neuronal cell bodies and proximal axonal processes, consistent with our findings in transfected COS-7 cells (Fig. 2 I-O).

It has been shown previously that in addition to the proteolytic processing of the $\mathrm{N}$-terminal signal peptide, cRGMa is cleaved once more to yield two proteolytic
A

CRGMa mRGMa MRGMb mRGMC

CRGMa mRGMa mRGMb mRGMC

CRGMa mRGMa mRGMb mRGMC

CRGMa

mRGMa mRGMb mRGMC

CRGMa mRGMa mRGM mRGMC

CRGMa mRGMa MRGMb mRGMC

CRGMa mRGMa mRGMb mRGMC

CRGMa mRGMa mRGMb mRGMC

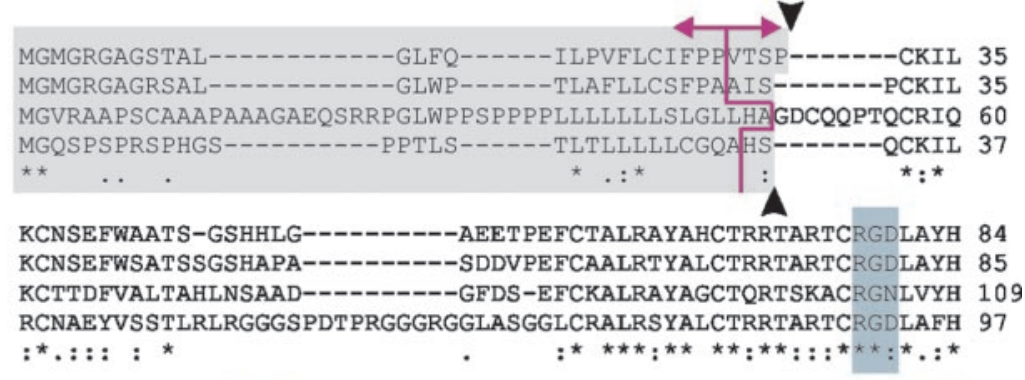

SAVHGIDDLMVQHNCSKDGPTSQPRLRTLPP-GDSQERSDSPEICHYEKSFHKHSAAPNY 143 SAVHGIEDLMSQHNCSKDGPTSQPRVRTLPPAGDSQERLDSPEICRYEKSFHKHSAAPNY 145 SAVLGISDLMSQRNCSKDGPTSSTNPEVTHDPCNYHSHGGVREHGGGDQ------RPPNY 163 SAVHGIEDLMIQHNCSRQGPTAPPPARGPALPGAGPAPLTPDPCDYEARFSRLHGRAPGF 157

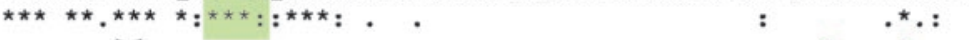
$\nabla$ THCGLFGDPHLRTFTDTFQTCKVQGAWPLIDNNYLNVQVTNTPVLPGSSATATSKLTIIF 203 THCGLFGDPHLRTFTDHFQTCKVQGAWPLIDNNYLNVQVTNTPVLPGSAATATSKLTIIF 205 LFCGLFGDPHLRTFKDHFQTCKVEGAWPLIDNNYLSVQVTNVPVVPGSSATATNKVTIIF 223 LHCASFGDPHVRSFHNQFHTCRVQGAWPLLDNDFLFVQATSSPVSSGANATTIRKITIIF 217

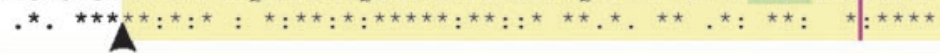

KSFQECVEQKVYQAEMDELPAAFADGSKNGGDKHGANSLKITEKVSGQHIEIQAKYIGTT 263 KNEQECVDQKVYQAEMDELPSAFADGSKNGGDKHGANSLKITEKVSGQHVEIQAKYIGTT 265 KAQHECTDQKVYQAVTDDLPAAFVDGTTSGGDGD-VKSLHIVEKESGRYVEMHARYIGTT 282 KNMQECIDQKVYQAEVDNLPAAFEDGSINGGDRPGGSSLSIQTANLGSHVEIRAAYIGTT 277

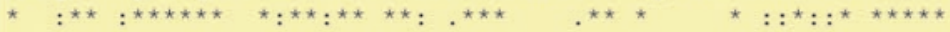

IVVRQVGRYLTFAVRMPEEVVNAVEDRDSQGLYLCLRGCPLNQQIDFQTFRLAQAAEGRA 323 IVVRQVGRYLTFAVRMPEEVVNAVEDRDSQGLYLCLRGCPLNQQIDFQAFRANAESPRRP 325 VFVRQLGRYLTLAIRMPEDLAMSYE--ESQDLQLCVNGCPMSECID-DGQGQVSAILGHS 339 IIIRQTAGQLSFSIRVAEDVARAFS--AEQDLQLCVGGCPPSQRLS------------- 321

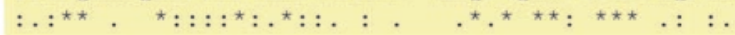

RRKGPSLPAPPEAFTYESATAKCREKLPVEDLYFOSCVFDLLTTGDVNFMLAAYYAFEDV 383 AAASPS-PVVPETFPYETAVAKCKEKLPVEDLYYQACVFDLLTTGDVNETLAAYYALEDG 384 LPHTTSVQAWPG-YTLETASTQCHEKMPVKDIYFQSCVFDLLTTGDANFTAAAHSALEDV 398 ---- RSERNRRGAIAIDTARRLCKEGLPVEDAYFQSCVFDVSVSGDPNETVAAQTALDDA 377 ${ }^{\star} \quad .::^{\star} \quad{ }^{\star}:{ }^{\star}{ }^{\star \star}:{ }^{\star}{ }^{\star}:{ }^{\star}:{ }^{\star \star \star \star}: .:{ }^{\star \star}{ }^{\star \star} \quad{ }^{\star \star} \quad:^{\star}$ KMLHSNKDKLHLYERTRALAPGNAAPSEHPWALPALWVALLSLS--QCWLGLL- 434 KMLHSNKDKLHLFERTRELPGAVAAAAAAATTFPLAPQILLGTIPLLVLLPVLW 438 EALHPRKERWHIFPSS------CGGCRDLPVGLGLTCLILIMFL--------- 436 RVFLTDLENLHLFPSD-------AGPPLSPAICLVPLLSALFVLWLCFSK--- 420 . : $:{ }^{\star}:$ : $\mathbf{A}$.
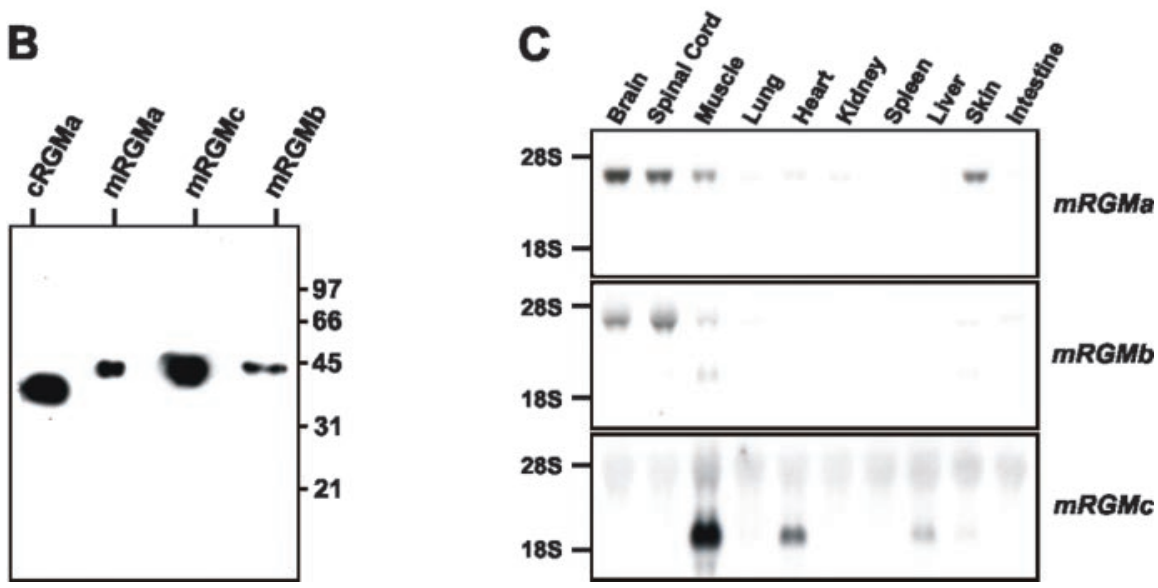

Figure 1. Characterization of the murine RGM protein family. A, Protein sequence alignment of $c R G M a, m R G M a, m R G M b$, and mRGMc. Asterisks indicate identical amino acids; pink lines, intron- exon junctions; the gray box, predicted signal peptides; the blue box, potential integrin binding sites (RGD); green boxes, predicted $N$-glycosylation sites; the yellow box, mature C-terminal RGM fragments after full proteolytic cleavage and C-terminal GPI anchor addition (proteolytic cleavage sites indicated by arrowheads). $B$, Western blot analysis of supernatant collected from COS-7 cells transfected with C-terminally truncated histidine-Myc-labeled CRGMa, mRGMa, mRGMc, and mRGMb detected with an anti-Myc antibody. Molecular weight standards in kilodaltons are indicated on the right. $C$, Northern blot analysis on total RNA from a variety of $\mathrm{P} 3$ mouse tissues as indicated, using $m R G M a, m R G M b$, and $m R G M c$ as probes. 


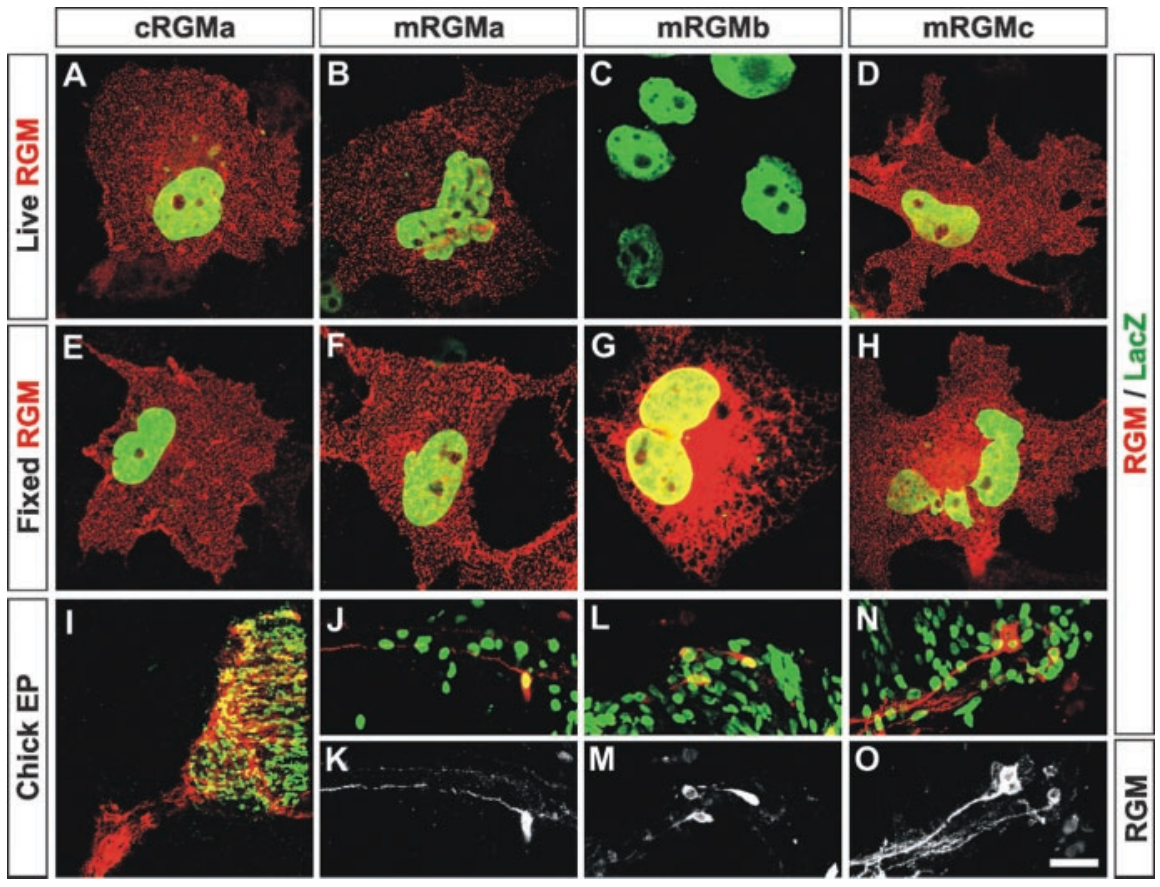

Figure 2. Differential cell-surface targeting of $m R G M s$. $A-H$, Expression of full-length cDNAs coding for $C R G M a(A, E)$, mRGMa $(B, F), \operatorname{mRGMb}(C, G)$, and $\mathrm{mRGMc}(D, H)$ and $\beta$-galactosidase on the same plasmid using an internal ribosome entry site in $C O S-7$ cells. Transfected COS-7 cells are identified by staining for $\beta$-galactosidase after the fixation and permeabilization of cells (green). RGMs (red) are detected either before fixation and permeabilization of cells $(A-D)$ to detect cell-surface-accumulated RGM or after fixation and permeabilization of cells $(E-H)$ to detect all RGM in transfected cells. $I-0$, Chick spinal cords electroporated with CDNAs coding for $C R G M a(I), \operatorname{mRGMa}(J, K), \operatorname{mRGMb}(L, M)$, and $\operatorname{mRGMc}(N, 0)$ and $\beta$-galactosidase on the same plasmid using an IRES. Sections were stained for RGM (red:I, J, L, N; white: $K, M, 0$ ) and $\beta$-galactosidase (green:I, J, L,N). Note the extensive labeling of axonal processes in $I, J, K, N$, and $O$ and the predominant cell-body and proximal axonal labeling in $L$ and $M$. Scale bar: (in 0 ) $A-H$, $15 \mu \mathrm{m} ; l, 150 \mu \mathrm{m} ; J-0,60 \mu \mathrm{m}$.

fragments, an N-terminal fragment containing an integrinbinding RGD motif and a C-terminal GPI-anchored fragment (Monnier et al., 2002). To determine whether this is also the case for mRGM proteins, we expressed mRGMa, mRGMb, and mRGMc in COS-7 cells, replacing the GPI anchor consensus sequence by a Myc-labeled hexahistidine tag. The molecular weights of these mRGM proteins collected from COS-7 cell supernatants were $\sim 42 \mathrm{kDa}$, whereas the molecular weight of cRGMa expressed using the same strategy was $\sim 35 \mathrm{kDa}$ (Fig. $1 B$ ). Nevertheless, $\mathrm{N}$-terminal end sequencing using Edman degradation showed identical cleavage sites within cRGMa, mRGMa, mRGMb, and mRGMc (Fig. 1A). The difference in the detected molecular weight is most likely caused by glycosylation (Fig. $1 A$, green boxes) or other post-translational modifications. In summary, the three murine members of the RGM family are proteolytically processed in a manner analogous to cRGMa, but whereas mRGMa and mRGMc are transported to the plasma membrane, $\mathrm{mRGMb}$ appears to be predominantly accumulated in intracellular compartments.

\section{Differential expression of mRGM family members during development}

Using a Northern blot analysis we found that the most abundant expression of $m R G M a$ and $m R G M b$ was detected in the nervous system, whereas $m R G M c$ was expressed predominantly in striated muscle tissues, with the highest level of expression detected in skeletal muscles (Fig. 1C). To determine the specific sites of expression of $m R G M a$ and $m R G M b$ during embryonic development, we performed in situ hybridization experiments. Both $m R G M a$ and $m R G M b$ are expressed specifically at the tips of the neural folds of mouse embryos from E8 to E9, coincident with the expression of mEphrinA5 (Fig. 3A-C) (Holmberg et al., 2000). Later, both $m R G M a$ and $m R G M b$ are expressed at discrete sites in the developing CNS, but in nonoverlapping and highly complementary patterns. $m R G M a$ expression in the brain is found surrounding the ventricles, whereas $m R G M b$ expression is often found laterally apposed to $m R G M a$ in early postmitotic neurons (Fig. $3 E-G$, E12.5 spinal cord; $H-K$, E14.5 thalamus). In addition, a high level of $m R G M b$ expression was also detected in developing dorsal root ganglia (DRG) (Fig. 3F, G) and at later developmental stages, $m R G M a$ and $m R G M b$ are also expressed in distinct nuclei of the brain (E17.5; data not shown). Consistent with the data from our Northern blot analysis, the expression of $m R G M c$ is confined to striated muscles, where it is found in both the muscles of the extremities (Fig. $3 L-O$ ) and of the face (Fig. 3J,K). No expression of $m R G M c$ was detected in embryonic brain or spinal cord (Fig. 3J; data not shown).

In summary, the most striking feature revealed by this in situ hybridization analysis was an essentially complete lack of overlap and a strong complementarity in the expression of $m R G M a$ and $m R G M b$ in the developing nervous system. Whereas $m R G M a$ expression is consistently found in subventricular zones surrounding the ventricles, $m R G M b$ expression is often found laterally apposed to $m R G M a$ and $m R G M c$ is expressed predominantly in skeletal muscles.

\section{Expression analysis of mouse RGMs in the visual system}

To address which of the mouse RGM family members might play a dominant role in the development of the retinocollicular system, we performed in situ hybridization experiments in the mouse superior colliculus at P0, a stage just before targeting of RGC axons to defined anteroposterior positions occurs (Simon and O'Leary, 1992). We found that $m R G M a$, the closest homolog of $c R G M a$, was prominently expressed in the superior colliculus at this stage (Fig. $4 A, D$ ). However, in contrast to chick (Monnier et al., 2002) (Fig. $4 F$ ), we failed to detect a gradient in the level of $m R G M a$ expression along the anteroposterior axis of the superior colliculus (Fig. $4 A, D$ ). In addition, and as described previously, $m$ EphrinA5 was expressed in a clear anteroposterior gradient in the mouse superior colliculus (Fig. 4B,E) (Frisen et al., 1998; Feldheim et al., 2000). At earlier developmental stages (E15.5), $m R G M a$ is also expressed prominently in the superior colliculus, whereas only faint expression of $m R G M b$ was detected (Fig. $4 G-$ $I)$. In the retina, $m R G M b$ but not $m R G M a$ or $m R G M c$ is expressed in RGCs (Fig. $4 J-L$ ). Thus, the $m R G M$ family member expressed most prominently in the superior colliculus, at a time just before targeting of RGC axons to defined anteroposterior positions occurs, is $m R G M a$. 


\section{Generation of mRGMa mutant mice}

To investigate the function of $m R G M a$ in retinocollicular topographic mapping, we performed homologous recombination in embryonic stem cells to eliminate $m R G M a$ gene function. We replaced the exon encoding the N-terminal signal peptide responsible for targeting mRGMa protein to the endoplasmic reticulum with a TKneomycin cassette (Fig. 5A). The transfection of a cDNA construct coding for the remaining $\mathrm{C}$-terminal exons of mRGMa into COS-7 cells showed that none of the transfected $\left(\mathrm{eGFP}^{+}\right)$COS-7 cells expressed the C-terminal fragment of mRGMa, thus demonstrating that all cellsurface-targeted mRGMa protein is eliminated with this targeting strategy (Fig. $5 E-H)$.

Successful homologous recombination in embryonic stem cells using this targeting construct was detected at a very low frequency $\quad(\sim 1: 2000)$. Heterozygous $m R G M a^{+/-}$mice were phenotypically normal, and interbreeding resulted in the generation of homozygous viable $m \mathrm{RGMa}^{-1-}$ mice (Fig. 5I; data not shown). Both PCR from genomic DNA as well as RT-PCR from total RNA of homozygous $m R G M a^{-1-}$ mice showed successful elimination of the exon encoding the signal peptide of mRGMa (Fig. $5 C, D$ ). Although $m R G M a^{-/-}$mice were detected at postnatal stages, the frequency of recovered viable mutants was non-Mendelian (Fig. 5I).

\section{Mutation in mRGMa results in an exencephalic phenotype in utero}

To assess whether a fraction of $m R G M a^{-1-}$ embryos die in utero, we examined the frequency and appearance of $m R G M a^{-/-}$embryos at various prenatal stages. At E16.5, we recovered two phenotypically different types of $m R G M a^{-1-}$ embryos: $\sim 50 \%$ of $m R G M a^{-1-}$ embryos had an appearance indistinguishable from wild-type embryos (Fig. 5I; data not shown), whereas in the remaining $\sim 50 \%$ of $m \mathrm{RGMa}^{-1-}$ embryos, the brain was exposed to the exterior environment and cranial skull tissue was absent (Figs. 5I, $6 D)$. Dissection of the brains from these affected $m R G M a^{-1-}$ embryos revealed that the ventral side of the brains as well as the brainstem and spinal cord were anatomically normal compared to wild-type brains and spinal cords (Fig. 6E,F). In contrast, dorsal and lateral views of the brain from affected $m R G M a^{-1-}$ embryos revealed major defects in the morphogenesis of dorsal brain structures (Fig. 6B,E; data not shown).

To define the nature of the observed defects more precisely,
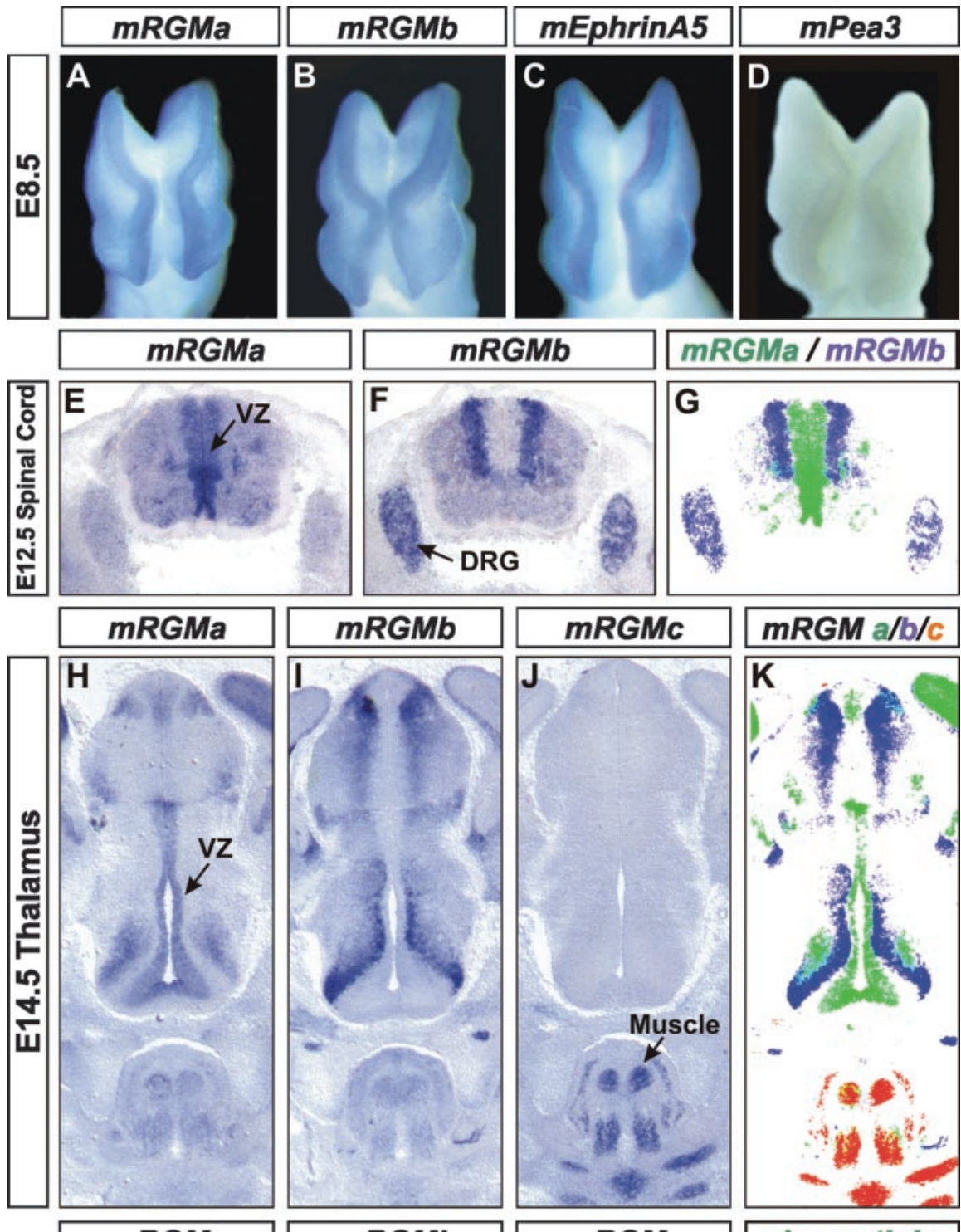

$m R G M a / b / c$
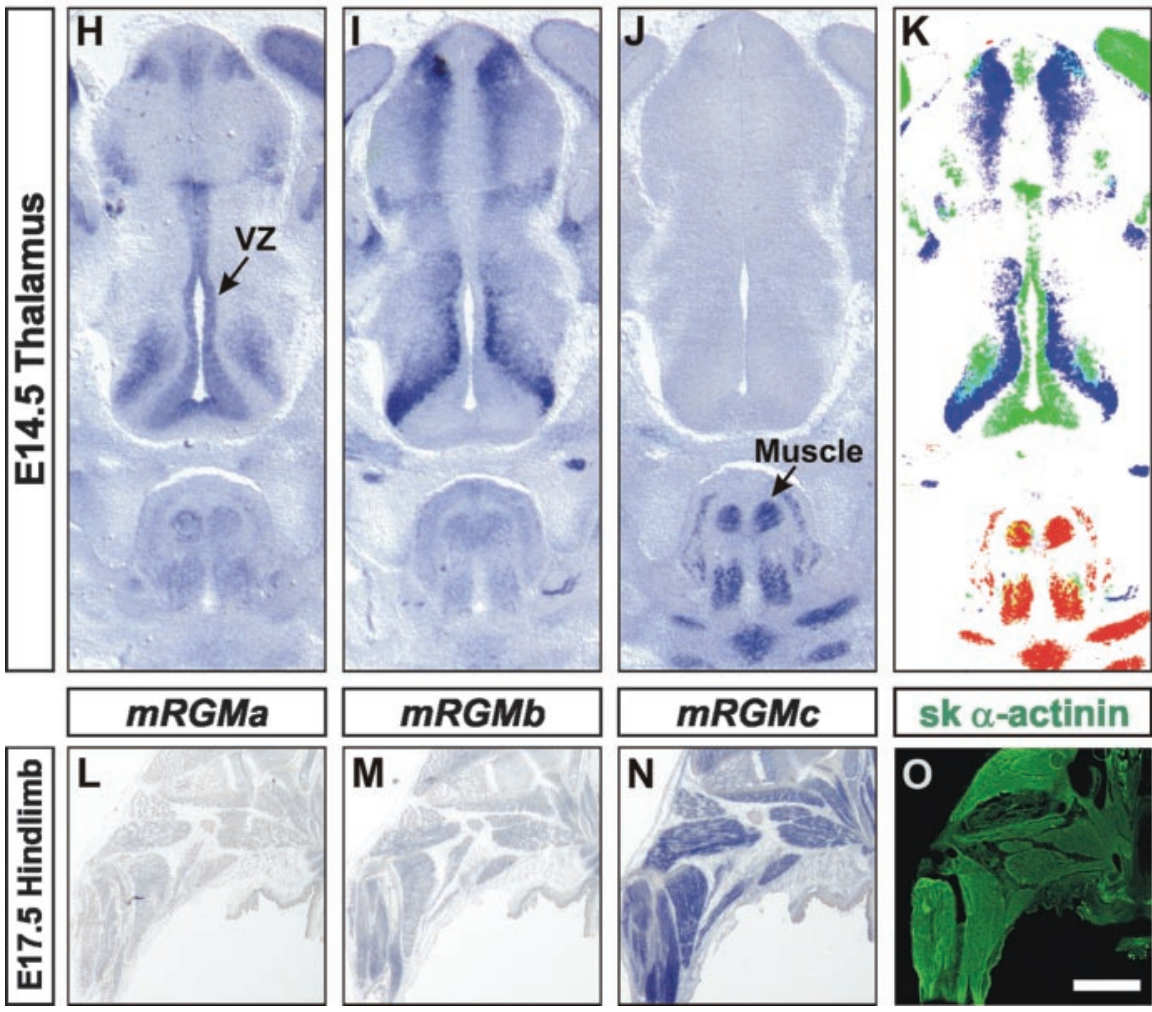

Figure 3. Embryonic expression of $m R G M s$ in complementary patterns. $A-D$, Whole-mount in situ hybridization of $E 8.5$ mouse embryos using $m R G M a(A), m R G M b(B), m E p h r i n A 5(C)$, and $m P e a 3(D)$ as probes. Note the absence of $m P e a 3$ expression from the tips of neural folds. $E-G$, Expression of $m R G M a(E)$ and $m R G M b(F)$ in E12.5 mouse spinal cord. Arrows point to the ventricular zone (VZ) in $E$ and the DRG in $F$, detected by in situ hybridization on transverse sections. $G$, Artificial overlay ( $m R G M a$ in green, $m R G M b$ in blue) to demonstrate complementarity of expression patterns. $H-K$, Expression of $m R G M a(H, V Z), m R G M b(I)$, and $\operatorname{mRGMC}(J)$ in E14.5 mouse thalamus by in situ hybridization on coronal brain sections. The arrow in $J$ points to the signal of $m R G M c$ in skeletal muscles. $K$ shows an artificial overlay ( $m R G M a$ in green, $m R G M b$ in blue, and $m R G M c$ in red) to demonstrate the complementarity of expression patterns. $L-0$, Expression of $m R G M a(L), m R G M b(M)$, and $m R G M c(N)$ by in situ hybridization and skeletal $\alpha$-actinin ( 0 ) by immunohistochemistry on $E 17.5$ mouse hindlimbs. Scale bar: (in 0$) A-D$, $0.15 \mathrm{~mm} ; E-G, 0.35 \mathrm{~mm} ; H-K, 0.32 \mathrm{~mm} ; L-0,1.8 \mathrm{~mm}$.

we performed a time course analysis at different embryonic stages. At E8, all $m R \mathrm{GMa}^{-1-}$ embryos were indistinguishable from wild-type embryos (data not shown). By E8.5-E9, when the closure of neural folds in wild-type embryos has been initiated at 


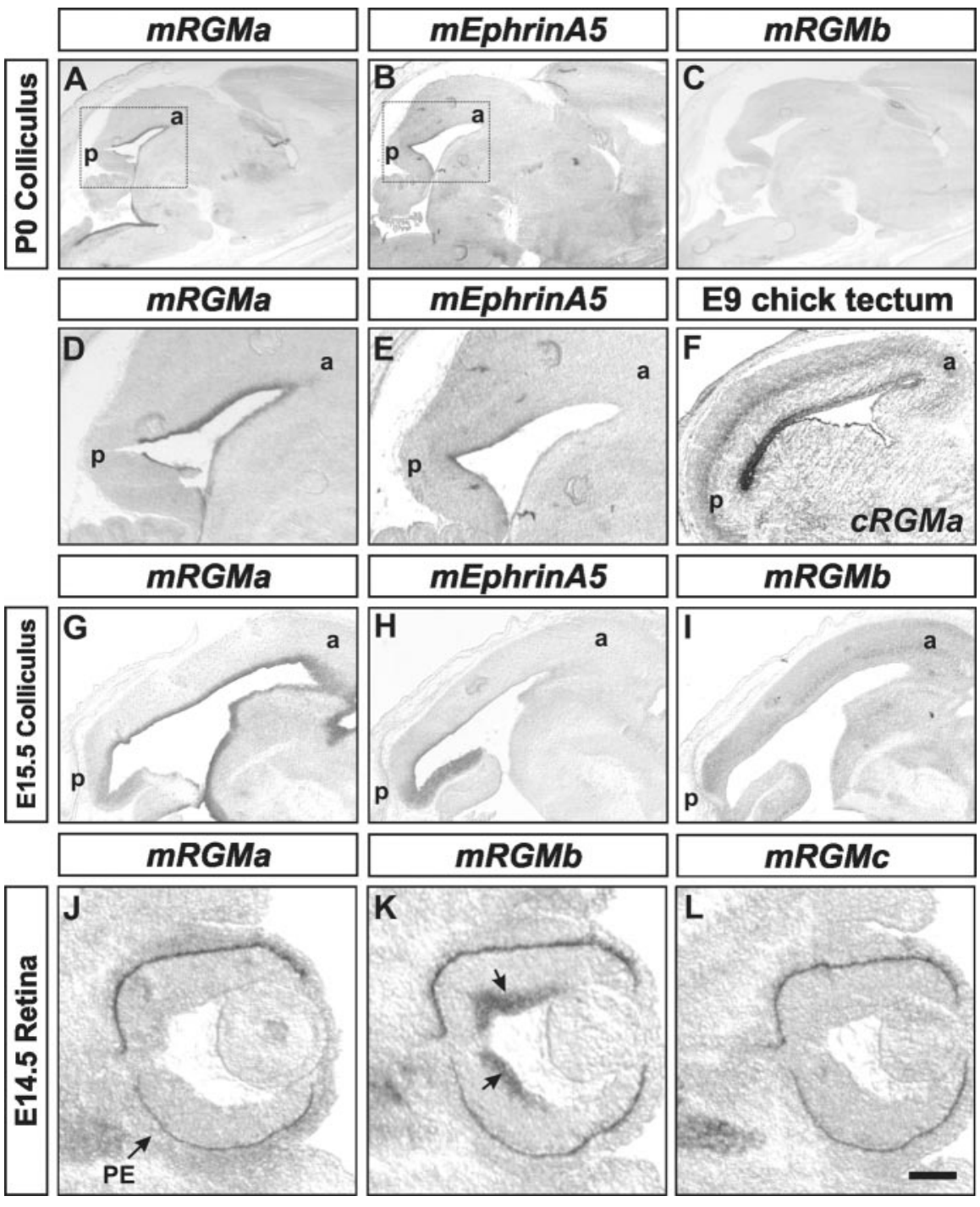

Figure 4. Expression of $m R G M$ s in the developing retinocollicular system. $A-E$, Expression of $m R G M a(A, D), m E$ phrinA5 $(B, E)$, and $m R G M b(C)$ in the superior colliculus of $\mathrm{PO}$ sagittal brain sections detected by in situ hybridization. Boxes in $A$ and $B$ indicate regions shown in higher magnification in $D$ and $E$. a, Anterior; p, posterior. $F$, Expression of $(R G M a$ in $E 9$ chick tectum detected by in situ hybridization. $G-I$, Expression of $m R G M a(G), m E p h r i n A 5(H)$, and $m R G M b$ (long exposure to detect faint expression; $I$ ) in the superior colliculus of E15.5 sagittal brain sections detected by in situ hybridization. $J-L$, Expression of $m R G M a(J), m R G M b(K)$, and $m R G M c(L)$ in E14.5 retina detected by in situ hybridization. Note the expression of $m R G M b$ in RGCs ( $K$, arrows). Pigment epithelium is marked by an arrow in $J$. Scale bar: (in $L) A-C, 1 \mathrm{~mm} ; D, E, 0.4 \mathrm{~mm} ; F, 0.85 \mathrm{~mm} ; G-I, 0.25 \mathrm{~mm} ; J-L, 0.13 \mathrm{~mm}$.
(Harris and Juriloff, 1997). Exencephalic $m R \mathrm{Ma}^{-/-}$embryos removed surgically immediately before birth (E19) displayed reflexive motion and breathing behavior but died shortly thereafter (data not shown). In contrast, exencephalic $m R G M a^{-1-}$ embryos delivered by natural birth were stillborn and anencephalic (lacking brain tissue entirely), presumably because of a lack of protection of the brain by the overlying skull during the process of birth (data not shown).

These findings suggest that an early function of $m R G M a$ at the site of neural tube closure where both $m R G M a$ and $m R G M b$ are expressed at this time may be responsible for the exencephalic phenotype observed in $\sim 50 \%$ of $m R G M a^{-1-}$ embryos.

\section{Exencephalic mRGMa mutants show no} defects in early brain patterning

Does the absence of $m R G M a$ lead to defects in neuronal patterning, cell proliferation, or apoptosis? We first performed BrdU pulse labeling experiments to assess proliferation and neuronal differentiation in $m R G M a^{-1-}$ embryos. We found that the amount of cellular proliferation was not obviously changed in either exencephalic or anatomically normal $m R G M a^{-1-}$ embryos compared with wild-type brains or spinal cords (Fig. 7A-H; data not shown). However, because of the lack of brain closure in exencephalic $m R G M a^{-1-}$ embryos, proliferating cells in dorsal brain structures now appeared on the outside of the brain, whereas $\mathrm{GAP} 3^{+}$differentiating neurons were facing the lumen (Fig. $7 B, D, F, H$ ). $\mathrm{BrdU}^{+}$and $\mathrm{GAP}^{+}{ }^{+}$cells were not intermingled in exencephalic $m R G M a^{-1-}$ embryos, indicating that $m R G M a$ is not required for the initial segregation of proliferating cells and differentiating neurons in the brain. We also did not find defects in cellular proliferation and panboth cephalic and spinal cord levels (Theiler, 1989), 50\% of $m R G M a^{-1-}$ embryos did not show signs of efficient cephalic closure, leading to a lack of closure at the cephalic level by E10.5 (Fig. 6G-J; data not shown). In contrast, the closure of the neural folds at the level of the spinal cord was never affected in $m R G M a^{-1-}$ embryos (Fig. 6I,J; data not shown). This defect has been described previously as exencephaly (Harris and Juriloff, 1997). Exencephaly is caused by a failure of the cephalic neural folds to fuse, resulting in an exvagination of the developing cephalic tissue at later developmental stages, when many neurons are born and brain size increases (Harris and Juriloff, 1997). By E14.5, exencephalic $m R G M a^{-1-}$ embryos show a pronounced exposure of the developing brain structures and third ventricle to the external environment, as well as a lack of development of cranial skull tissue (Fig. $6 \mathrm{~K}-\mathrm{N}$ ). In addition, the exencephalic tissue of $m R \mathrm{GMa}^{-1-}$ embryos was highly vascularized (Fig. $6 E, L)$, another feature frequently observed in exencephalic brains neuronal differentiation in the spinal cords of $m R G M a^{-1-}$ embryos (data not shown). Similarly, many genes expressed in defined cell types of the brain and spinal cord were expressed normally in $m R G M a^{-1-}$ embryos (data not shown). In addition, no aberrant increase or decrease in apoptotic cell death could be observed in cephalic neural folds of exencephalic $m R G M a^{-1-}$ embryos at E8.5 (Fig. 7I,J). Together, these findings suggest that the exencephalic phenotype observed in a subpopulation of $m R G \mathrm{Ma}^{-1-}$ embryos is most likely not caused by defects in neuronal patterning or cell proliferation, nor does the exencephalic phenotype caused by absence of $m R G M a$ lead to such defects.

\section{Viable mRGMa mutants show no defects in anteroposterior retinocollicular projections}

To determine whether the surviving $m R G M a^{-1-}$ mice show defects in the anteroposterior mapping of retinocollicular projections, as suggested from in vitro studies in the developing chick 


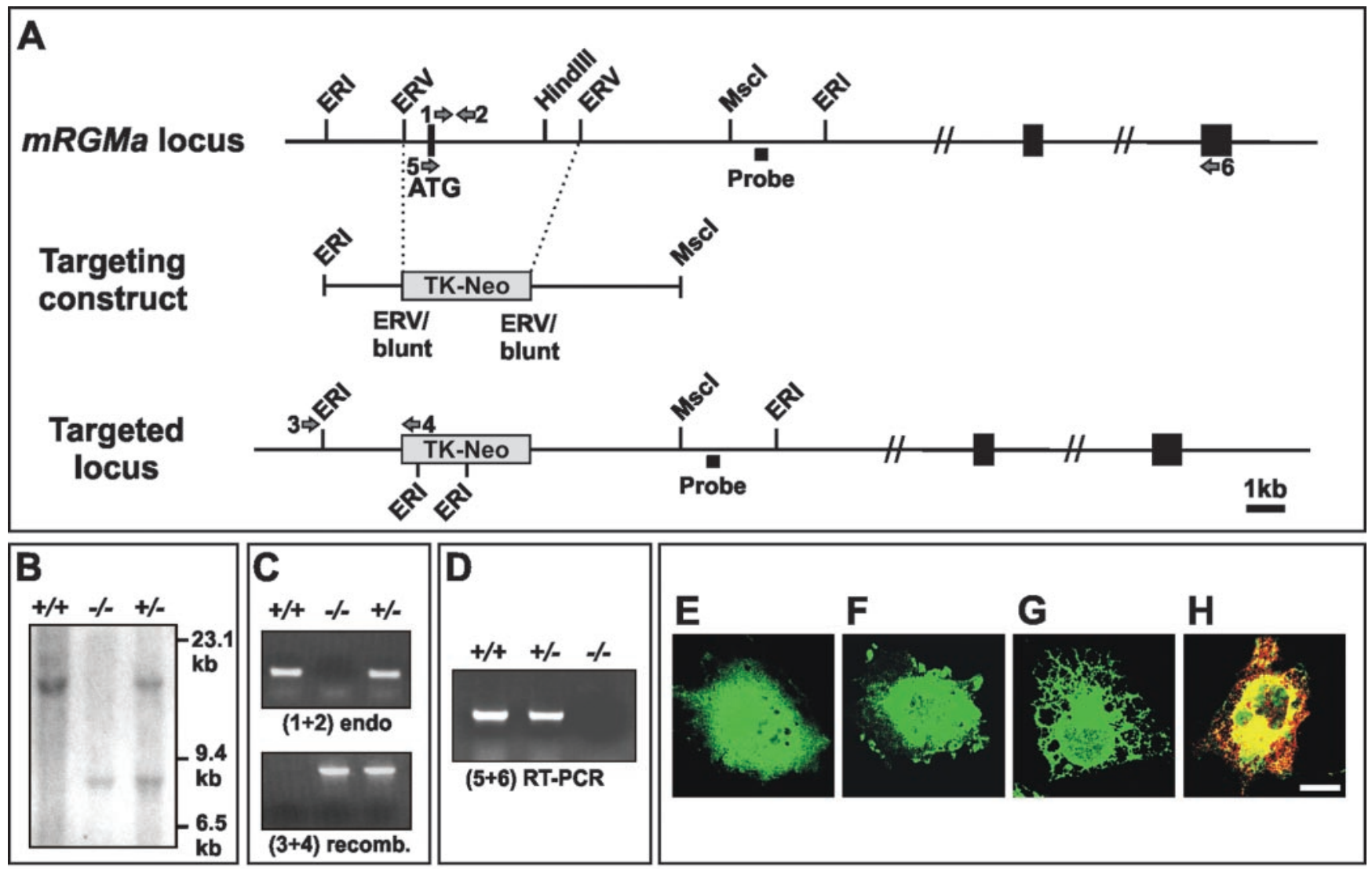

I

Offspring of $m R G M a^{* /} \times m R G M a^{*-}$

\begin{tabular}{|l|c|c|c|c|c|c|c|}
\hline & $m R G M a^{*+}$ & $m R G M a^{*+}$ & $m R G M a^{+}$ & exenc $m R^{*} M^{+}$ & total & $\%$ of $m R^{*} M^{+}$ & $\%$ of exenc $R G M a^{+}$ \\
\hline born alive & 126 & 245 & 47 & - & 418 & $11.2 \%$ & - \\
\hline embryonic & 52 & 81 & 44 & 20 & 177 & $24.5 \%$ & $11.3 \%$ \\
\hline
\end{tabular}

Figure 5. Generation of $m R G M a$ mutant mice. $A-D$, Targeting strategy for homologous recombination in ES cells to eliminate $m R G M a$ gene function. An EcoRV fragment including the exon containing the methionine of the signal peptide for targeting of mRGMa to the endoplasmic reticulum was replaced by a TK-neomycin resistant cassette (light gray). Coding exons for mRGMa and the probe used for genomic Southern analysis $(B)$ are indicated by black boxes. Oligonucleotides to determine the absence of the methionine-containing exon are indicated by arrows 1 and 2 ( $C$ ), oligonucleotides to verify $5^{\prime}$ homologous recombination by arrows 3 and $4(C)$, and oligonucleotides used for RT-PCR by arrows 5 and 6 (D). RT-PCR analysis (D) was used to verify the absence of the exon containing the signal peptide on $m R G M a$ mRNA in $m R G M a$ mutant mice (arrows 5 and 6 in A). E-H, Immunocytochemistry of COS-7 cells transfected with a cDNA construct containing mRGMa exons 3 ' of the targeted exon and eGFP on a bicistronic plasmid $(E, F)$ or a cDNA construct containing an additional artificial in-frame N-terminal methionine and an eGFP containing a signal peptide for targeting to the endoplasmic reticulum $(G, H)$. Cells were stained for eGFP (green) and $\mathrm{mRGMa}$ (red). In $E$ and $G$, the incubation of cells with antibody to mRGMa was performed before the fixation and permeabilization of cells to label cell-surface-associated mRGMa. In $F$ and $H$, the fixation and permeabilization of cells was performed before incubation with antibodies. Note that even the addition of an artificial $\mathrm{N}$-terminal methionine in frame with the C-terminal mRGMa exons did not result in cell-surface-exposed mRGMa after transfection $(G, H)$. Scale bar, $15 \mu \mathrm{m}$. I, Statistical analysis of the offspring recovered from matings of $\mathrm{mRGMa}^{+/-}$breeder pairs. exenc, Exencephalic $\mathrm{mRGMa}{ }^{-1-}$ embryos.

embryo (Monnier et al., 2002), we first injected the lipophilic tracer DiI into the eyes of $\mathrm{P} 0$ mice, attempting to label many RGC axons projecting from the retina to the brain. In viable $m R G M a^{-1-}$, as in wild-type mice, the entire superior colliculus was filled with axons and, as expected at this developmental stage (Simon and O'Leary, 1992), a significant number of axons also projected into the inferior colliculus $(n=5)$ (Fig. $8 A, B)$.

By P8, RGC axons within the superior colliculus have segregated into defined anteroposterior positions, reaching topographic positions found in the mature superior colliculus (Simon and O'Leary, 1992; Frisen et al., 1998). To determine whether in viable $m R G M a^{-1-}$ mice, retinocollicular axonal projections terminate in the appropriate anteroposterior position within the superior colliculus, we focally injected DiI into specific regions of the retina of P9-P12 animals. In this analysis, we first focused our attention on injections into the temporal RGC population known to project normally to the anterior and to be repelled by the posterior superior colliculus (Walter et al., 1987; Godement and Bonhoeffer, 1989; Roskies and O'Leary, 1994). Analysis of the projections of these $\mathrm{DiI}^{+}$temporal RGC axons showed a single focal termination zone, in the predicted anteroposterior position of both wild-type and viable $m R G M a^{-1-}$ mice $(n \geq 15)$ (Fig. $8 C, D)$. In addition, focal injections of DiI into the nasal retina of both wild-type and viable $m R G M a^{-1-}$ mice revealed that these axons also project and terminate normally in the posterior superior colliculus $(n=10)$ (Fig. $8 E, F)$. To assess whether the lack of phenotype observed in retinocollicular projections of viable $m R G M a^{-1-}$ mice could be caused by compensatory upregulation of either other $m R G M$ family members or members of the Ephrin family of genes, we performed in situ hybridization exper- 


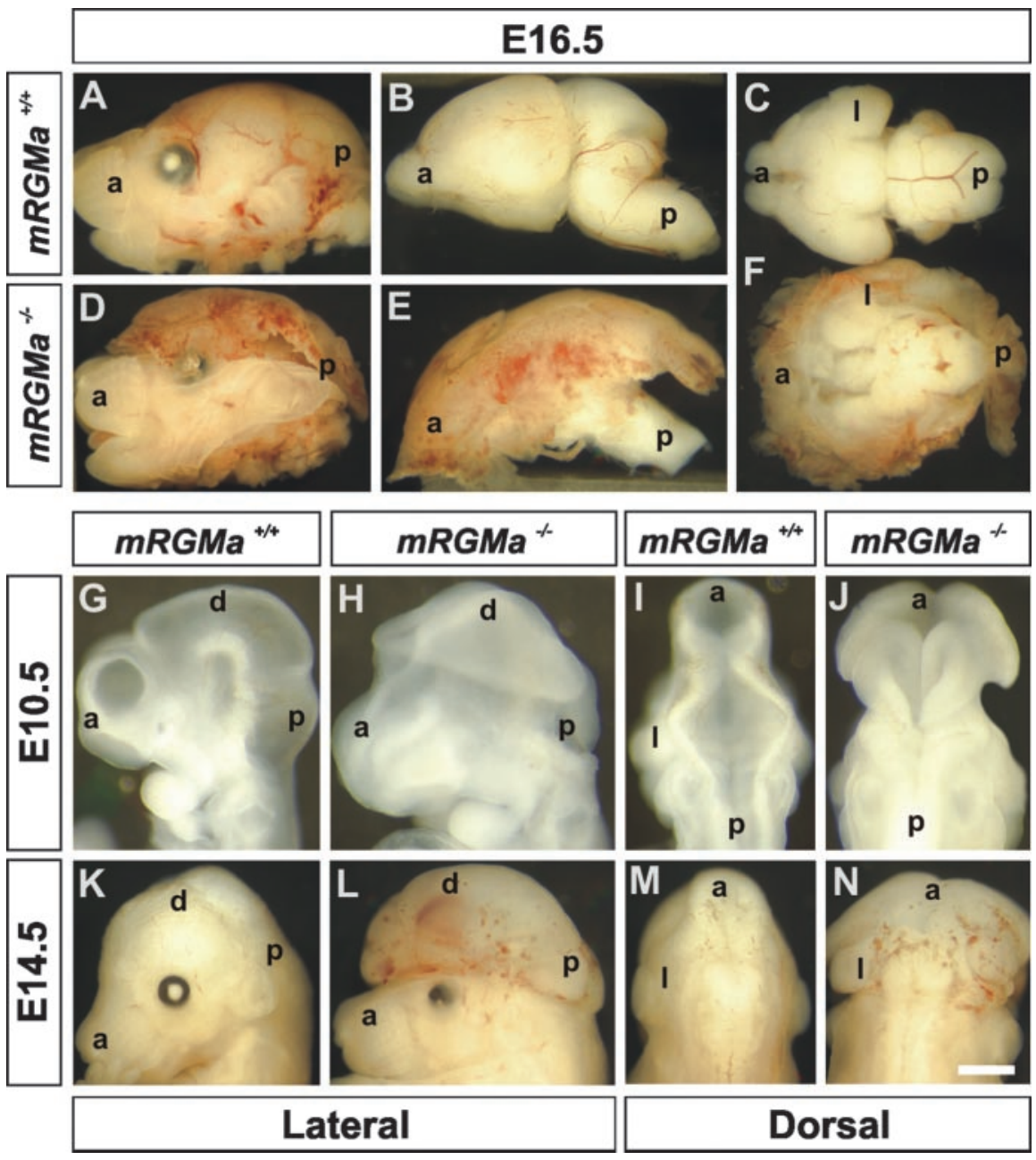

Figure 6. $m R G M a$ mutant mice show an exencephalic phenotype. $A-F$, Lateral $(A, B, D, E)$ or ventral $(C, F)$ view of E16.5 heads $(A, D)$ or dissected brains $(B, C, E, F)$ from $m R G M a^{+/+}(A-C)$ and exencephalic $m R G M a^{-1-}(D-F)$ embryos. $G-J$, Lateral $(G, H)$ or dorsal $(I, J)$ head view of E10.5 mRGMa ${ }^{+I+}(G, I)$ and $m R G M a^{-I-}(H, J)$ embryos. $K-N$, Lateral $(K, L)$ or dorsal $(M, N)$ head view of E14.5 $m R G M a^{+/+}(K, M)$ and $m R G M a^{-1-}(L, N)$ embryos. a, Anterior; p, posterior; d, dorsal; I, lateral. Scale bar: (in $N$ ) $A, D, 1.5 \mathrm{~mm} ; B, E, 1 \mathrm{~mm} ; C, F, 1.1 \mathrm{~mm} ; G-J, 0.6 \mathrm{~mm} ; K-N, 1.2 \mathrm{~mm}$.

iments. We found that expression of $m R G M b, m R G M c, E p h$ rinA2, and EphrinA5 in the superior colliculus of $m R G M a^{-1-}$ mice was not altered when compared with wild-type littermates (Fig. 8G-J). Together, these findings suggest that the lack of $m R G M a$ gene function does not seem to impair anteroposterior mapping of RGC axons to the superior colliculus.

\section{Discussion}

In this study we found that cRGMa is a member of a novel family of GPI-anchored proteins, of which we identified and characterized three murine members: mRGMa, mRGMb, and mRGMc. Two members of this gene family are expressed predominantly in the developing nervous system in nonoverlapping and distinct expression patterns ( $m R G M a$ and $m R G M b)$, whereas the third member is expressed most abundantly in skeletal muscles $(m R G M c)$. Previous in vitro studies in the chick have suggested that $c R G M a$ may play a role in the establishment of appropriate anteroposterior RGC termination zones within the tectum. Our functional studies in the mouse now showed that $m R G M a$ mutant mice did not exhibit defects in the development of topographically appropriate projections in the anteroposterior dimension of the superior colliculus. Instead, a significant proportion of $m R G M a$ mutant mice showed an exencephalic defect caused by failure of the cephalic neural tube to close during development. We will discuss these findings in the context of (1) the distinct sites of expression and subcellular localization of different RGM family members and (2) the in vivo function of $m R G M a$ in the developing mouse nervous system.

\section{Identification of a novel family of GPI- anchored proteins homologous to cRGMa}

The identification of three genes homologous to $c R G M a$ in the mouse genome has allowed us to study the precise developmental time course of expression, subcellular targeting, and proteolytic processing of these proteins. Two members of this gene family ( $m R G M a$ and $m R G M b$ ) show abundant expression in the developing mouse nervous system. It is interesting to note that the two genes expressed in the nervous system appear to have evolutionarily arisen by gene duplication. Preliminary evidence suggests that there is a homolog of $m R G M b$ in the chick genome with an expression pattern confined to the nervous system (R. Salie, V. Niederkofler, and S. Arber, unpublished observations), indicating that this gene duplication must have occurred evolutionarily earlier than in the chick. A striking feature we observed in the expression of $m R G M a$ and $m R G M b$ within the nervous system is that their sites of expression are highly distinct and nonoverlapping. Although $m R G M a$ is consistently expressed in ventricular zones in which proliferating cells are found, the expression of $m R G M b$ is almost exclusive to domains in which early postmitotic neurons are found and not in ventricular zones. In addition to these sites of expression, distinct groups of postmitotic neurons also express $m R G M a$ or $m R G M b$ in nonoverlapping patterns. In contrast, the third member of the family $(m R G M c)$ is expressed in skeletal muscles and is evolutionarily more distantly related to $m R G M a$ and $m R G M b$. Given the function of $m R G M a$ in controlling the process of alignment of dorsal neural folds ultimately leading to neural tube closure, it is tempting to speculate that $m R G M c$ might be involved in the process of myogenesis, during which mononucleated myoblasts fuse to form multinucleated myotubes. Consistent with this idea, $m R G M c$ expression is upregulated during the process of myogenic differentiation in vitro (Niederkofler, Salie, and Arber, unpublished observations).

All three mouse homologues of $c R G M a$ have predicted GPI anchor consensus sequences and undergo proteolytic cleavage at several sites within the protein, raising the question of the subcellular localization of the mature mRGM proteins. Our analysis revealed that there is an internal cleavage site within all three $\mathrm{mRGM}$ proteins that is highly conserved in sequence between the three mRGM members and cRGMa. This internal protein cleavage produces two fragments, one $\mathrm{N}$-terminal fragment contain- 

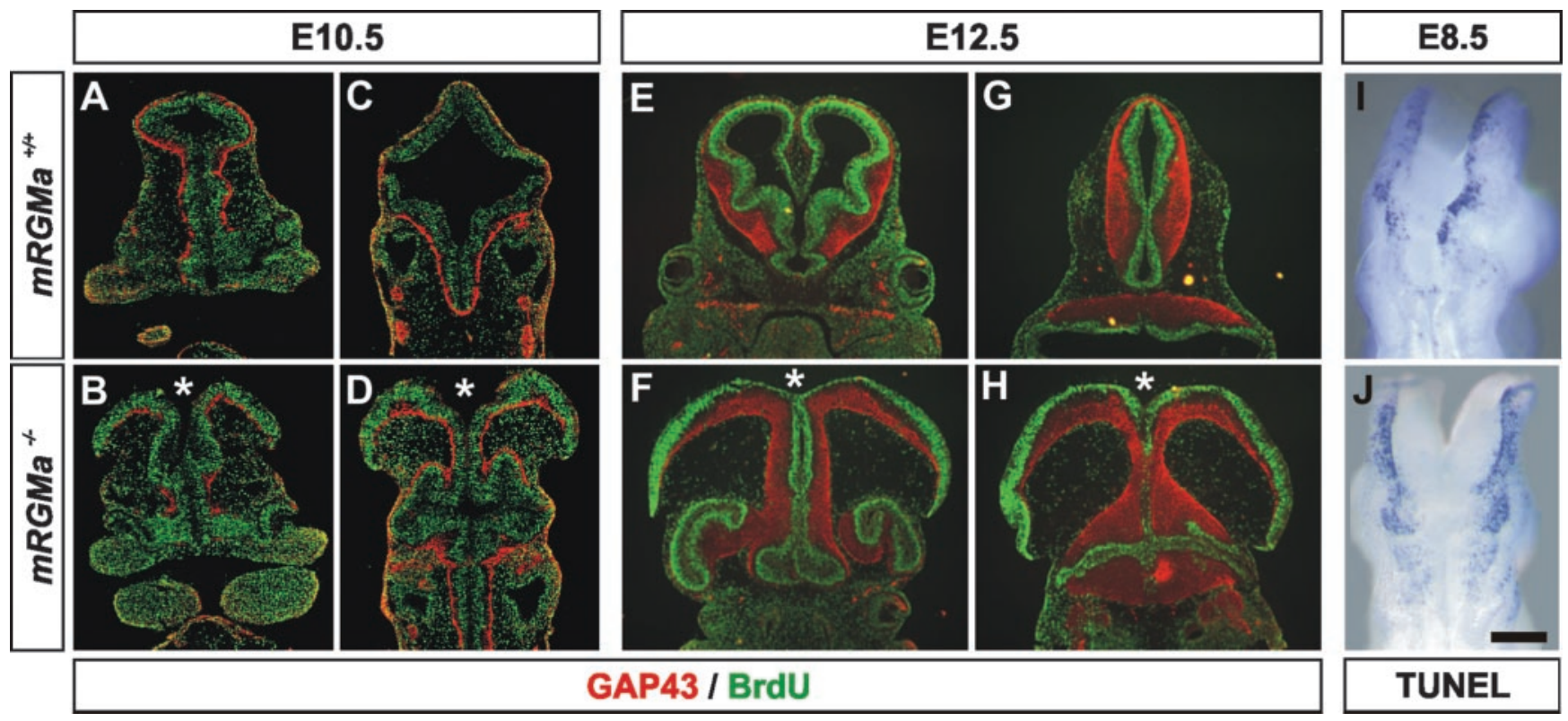

Figure 7. Exencephalic $m R G M a$ mutant embryos do not show defects in proliferation in the brain. $A-H$, Immunohistochemical analysis (GAP-43: red; BrdU: green) of coronal brain sections from E10.5 $(A-D)$ and E12.5 $(E-H)$ BrdU pulse-labeled $m R G M a^{+/+}(A, C, E, G)$ and exencephalicmRGMa ${ }^{-1-}(B, D, F, H)$ embryos. ${ }^{*}$ Open ventricle. I, J, Whole-mount TUNEL of E8.5 mRGMa ${ }^{+/+}(I)$ and exencephalic $m R G M a^{-I-}(J)$ embryos in dorsal view. Scale bar: (in J) $A, B, E, F, 0.38 \mathrm{~mm} ; C, D, G, H, 0.5 \mathrm{~mm} ; \mathrm{l}, J, 0.13 \mathrm{~mm}$.

ing an integrin-binding RGD site and a C-terminal fragment with a GPI anchor consensus site. To our knowledge, the sequence of this cleavage site has not been described previously in other proteins, and it will be interesting to determine which protease(s) recognize(s) this cleavage site and whether similar proteolytic cleavage sites are present in other proteins. In addition, such a protease may be expressed differentially in different cell types, leading to variable efficiencies in proteolytic processing depending on the amount and activity of protease present in a given cell type.

In contrast to the proteolytic cleavage reactions in the $\mathrm{N}$-terminal region detected in all mRGM proteins, subcellular targeting of different mRGM members to the cell surface does not occur with equal efficiency for all RGM family members. Although mRGMc is as efficiently targeted to the cell surface as cRGMa, less mRGMa and almost no mRGMb appears to reach the cell surface. This differential subcellular localization of the RGM family of proteins could be caused by differential efficiency in the addition of GPI anchors and may have important implications for the function of individual RGM family members in the extracellular space. Differential subcellular targeting has been suggested recently as a mechanism by which several proteins with proposed extracellular functions regulate their activities. For example, only small amounts of NogoA protein reach the cell surface of oligodendrocytes and the most prominent localization of NogoA is found in the endoplasmic reticulum (Chen et al., 2000; GrandPre et al., 2000). It has been suggested that NogoA protein may be released from oligodendrocytes only after lesion of the nervous system, thus preventing NogoA from acting under normal circumstances (Brittis and Flanagan, 2001). Moreover, Commissureless in Drosophila has recently been described to sort Roundabout, the receptor for the repulsive guidance molecule Slit, to the endosomal compartment to prevent commissural neurons from responding to Slit before midline crossing (Keleman et al., 2002). Similarly, differential in vivo processing and subcellular localization of different members of the RGM family of proteins could regulate the degree of activity in a particular cell.
In vivo function of $\mathrm{mRGMa}$ in the developing nervous system Two major candidate protein families have been implicated in anteroposterior topographic mapping in the retinocollicular system (McLaughlin et al., 2003). Ephrins and cRGMa have both been shown to exhibit comparable in vitro activities guiding RGC axons (Drescher et al., 1995; Cheng et al., 1995; Monschau et al., 1997; Monnier et al., 2002). However, whereas genetic evidence supports a role for Ephrins in anteroposterior topographic mapping in the superior colliculus (Feldheim et al., 2000; McLaughlin et al., 2003), our data on $m R G M a^{-1-}$ mice suggest that $m R G M a$ is not essential for this process. However, our findings reveal that although there does not appear to be a similarity in the phenotype of EphrinA $5^{-1-}$ and $m R G M a^{-1-}$ mice in the retinocollicular system, both $m R G M a$ and EphrinA5 are involved in the process of cephalic neural tube closure, albeit at a different level of genetic penetrance (Holmberg et al., 2000). Consistent with this phenotype, both EphrinA5 (Holmberg et al., 2000) and $m R G M a$ are expressed in the dorsal edges of the cranial neural folds.

Why do $m R G M a^{-1-}$ mice not show a defect in the establishment of anteroposterior retinocollicular topographic mapping? It is unlikely that a compensatory upregulation of gene expression of other $m R G M$ or Ephrin family member(s) can account for the lack of phenotype in retinocollicular mapping of $m R G M a^{-/-}$ mice because the expression of both $m R G M b$ and $m R G M c$ as well as EphrinA2 and EphrinA5 is unchanged in $m R G M a^{-1-}$ mice. Moreover, $m R G M a$ appears to be the member of the $m R G M$ gene family expressed at the highest level in the mouse superior colliculus at the time RGC axons segregate into their final anteroposterior position within the target region, suggesting that $m R G M a$ should play the dominant role among $m R G M$ family members in controlling RGC targeting. In contrast, developing RGCs express high levels of $m R G M b$ and no or only low levels of $m R G M a$. Because previous evidence suggests that the expression of Ephrins does not only contribute to the development of retinocollicular projections through expression in the target region itself but also through expression in RGCs (Hornberger et al., 1999), it will be interesting to determine in future experiments 

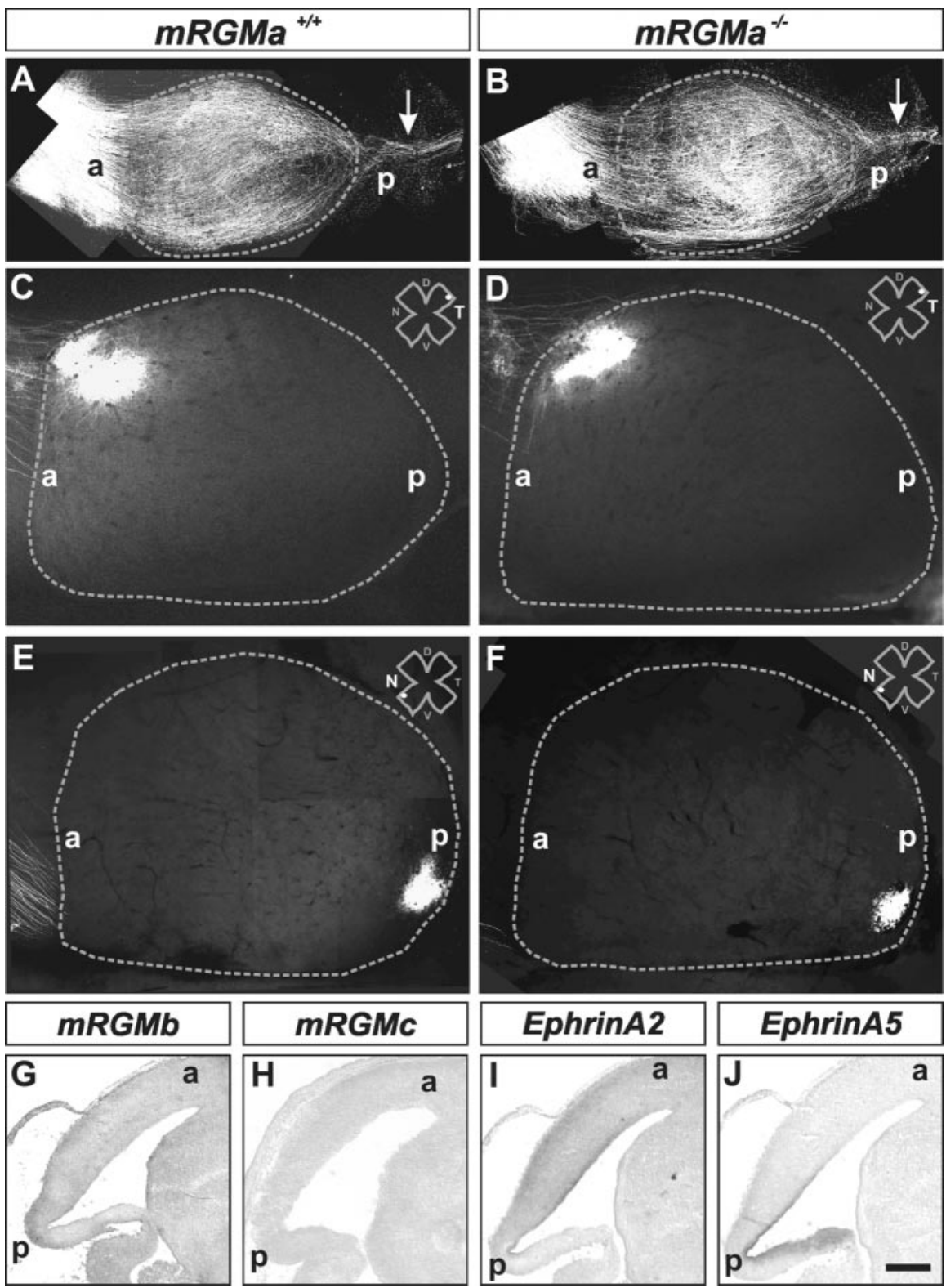

Figure 8. Lack of retinocollicular projection phenotype in $m R G M a$ mutant mice. $A, B$, Dorsal views of superior and inferior colliculi from $m R G M a^{+/+}(A)$ and $m R G M a^{-1-}(B)$ mice after anterograde Dil labeling from the retina at $P 0$ to label many RGC axons. The gray dashed line outlines the superior colliculus; arrows point to RGC axons projecting to the inferior colliculus. $C-F$, Anterograde Dil labeling from the temporal $(C, D)$ or nasal $(E, F)$ retina to the superior colliculus (outlined by gray dashed lines) after focal Dil injection into the retina of $m R G M a^{+/+}(C, E)$ and $m R G M a^{-/-}(D, F)$ mice at $P 10$ (injection point in the retina indicated by the white dot the top right corner: $\mathrm{T}$, Temporal; $\mathrm{N}$, nasal; D, dorsal; $\mathrm{V}$, ventral). $\mathrm{G}-$ J, Expression of $m R G M b(G), m R G M c$ $(H)$, $m$ EphrinA2 $(I)$, and $m E$ EhrinA5 $(J)$ in superior colliculi of E16.5 sagittal brain sections from $m R G M a^{-/-}$mice detected by in situ hybridization. a, Anterior; $p$, posterior. Scale bar: (in $J) A, B, 0.5 \mathrm{~mm} ;(-F, 0.33 \mathrm{~mm} ; G-J, 0.3 \mathrm{~mm}$.

how $m R G M b$ gene function contributes to the development of retinocollicular projections. The generation of $m R G M a / m R G M b$ double mutant mice should be able to address this question definitively in the future. Another possible explanation for a lack of phenotype in $m R G M a^{-1-}$ mice could come from the observation that although the expression of EphrinA2 and EphrinA5 in the mouse superior colliculus is graded (Feldheim et al., 2000), $m R G M a$ exhibits no such anteroposterior gradient. Thus, the function of $m R G M a$ may have changed during evolution, maybe because the chick tectum is significantly bigger than the mouse superior colliculus (McLaughlin et al., 2003) potentially requiring additional cues to acquire precision in the development of

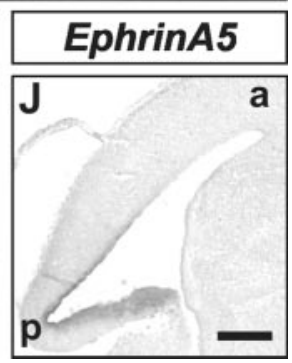

projections from the retina to the tectum. Alternatively, $m R G M a$ may function only in combination with EphrinA2 and EphrinA 5 present in the superior colliculus of the mouse and to reveal a retinocollicular phenotype may require the generation of mRGMa ${ }^{-1-} /$ EphrinA2 $2^{-1-} /$ EphrinA $5^{-1-}$ mice. It has indeed been suggested that in addition to EphrinA2 and EphrinA5 other guidance cues ought to be present in the mouse to explain the anteroposterior topographic mapping in the superior colliculus because disruption of both EphrinA2 and EphrinA5 does not lead to a complete loss in anteroposterior retinocollicular topography (Feldheim et al., 2000). Future work will determine whether $m R G M a$ does indeed act as a cofactor in combination with other guidance molecules to restrict RGC axons to their correct anteroposterior position in the superior colliculus.

\section{References}

Arber S, Han B, Mendelsohn M, Smith M, Jessell TM, Sockanathan S (1999) Requirement for the homeobox gene $\mathrm{Hb} 9$ in the consolidation of motor neuron identity. Neuron 23:659-674.

Briscoe J, Pierani A, Jessell TM, Ericson J (2000) A homeodomain protein code specifies progenitor cell identity and neuronal fate in the ventral neural tube. Cell 101:435-445.

Brittis PA, Flanagan JG (2001) Nogo domains and a Nogo receptor: implications for axon regeneration. Neuron 30:11-14.

Chen MS, Huber AB, van der Haar ME, Frank M, Schnell L, Spillmann AA, Christ F, Schwab ME (2000) Nogo-A is a myelin-associated neurite outgrowth inhibitor and an antigen for monoclonal antibody IN-1. Nature 403:434-439.

Cheng HJ, Nakamoto M, Bergemann AD, Flanagan JG (1995) Complementary gradients in expression and binding of ELF- 1 and Mek4 in development of the topographic retinotectal projection map. Cell 82:371-381.

Dickson BJ (2002) Molecular mechanisms of axon guidance. Science 298:1959-1964.

Drescher U, Kremoser C, Handwerker C, Loschinger J, Noda M, Bonhoeffer F (1995) In vitro guidance of retinal ganglion cell axons by RAGS, a $25 \mathrm{kDa}$ tectal protein related to ligands for Eph receptor tyrosine kinases. Cell $82: 359-370$

Eisenhaber B, Bork P, Eisenhaber F (1999) Prediction of potential GPI-modification sites in proprotein sequences. J Mol Biol 292:741-758.

Feldheim DA, Kim YI, Bergemann AD, Frisen J, Barbacid M, Flanagan JG (2000) Genetic analysis of ephrin-A2 and ephrin-A5 shows their requirement in multiple aspects of retinocollicular mapping. Neuron 25:563-574.

Frisen J, Yates PA, McLaughlin T, Friedman GC, O'Leary DD, Barbacid M (1998) Ephrin-A5 (AL-1/RAGS) is essential for proper retinal axon guidance and topographic mapping in the mammalian visual system. Neuron 20:235-243.

Godement P, Bonhoeffer F (1989) Cross-species recognition of tectal cues by retinal fibers in vitro. Development 106:313-320.

GrandPre T, Nakamura F, Vartanian T, Strittmatter SM (2000) Identification of the Nogo inhibitor of axon regeneration as a Reticulon protein. Nature 403:439-444 
Harris MJ, Juriloff DM (1997) Genetic landmarks for defects in mouse neural tube closure. Teratology 56:177-187.

Holmberg J, Clarke DL, Frisen J (2000) Regulation of repulsion versus adhesion by different splice forms of an Eph receptor. Nature 408:203-206.

Hornberger MR, Dutting D, Ciossek T, Yamada T, Handwerker C, Lang S, Weth F, Huf J, Wessel R, Logan C, Tanaka H, Drescher U (1999) Modulation of EphA function by coexpressed ephrinA ligands on retinal ganglion cell axons. Neuron 22:731-742.

Keleman K, Rajagopalan S, Cleppien D, Teis D, Paiha K, Huber LA, Technau GM, Dickson BJ (2002) Comm sorts robo to control axon guidance at the Drosophila midline. Cell 110:415-427.

Livet J, Sigrist M, Stroebel S, De Paola V, Price SR, Henderson CE, Jessell TM, Arber S (2002) ETS gene Pea3 controls the central position and terminal arborization of specific motor neuron pools. Neuron 35:877-892.

McLaughlin T, Hindges R, O'Leary DD (2003) Regulation of axial patterning of the retina and its topographic mapping in the brain. Curr Opin Neurobiol 13:57-69.

Monnier PP, Sierra A, Macchi P, Deitinghoff L, Andersen JS, Mann M, Flad M, Hornberger MR, Stahl B, Bonhoeffer F, Mueller BK (2002) RGM is a repulsive guidance molecule for retinal axons. Nature 419:392-395.

Monschau B, Kremoser C, Ohta K, Tanaka H, Kaneko T, Yamada T, Handwerker C, Hornberger MR, Loschinger J, Pasquale EB, Siever DA, Verderame MF, Muller BK, Bonhoeffer F, Drescher U (1997) Shared and distinct functions of RAGS and ELF-1 in guiding retinal axons. EMBO J 16:1258-1267.

Nakamoto M, Cheng HJ, Friedman GC, McLaughlin T, Hansen MJ, Yoon CH, O'Leary DD, Flanagan JG (1996) Topographically specific effects of
ELF-1 on retinal axon guidance in vitro and retinal axon mapping in vivo. Cell 86:755-766.

Nielsen H, Brunak S, von Heijne G (1999) Machine learning approaches for the prediction of signal peptides and other protein sorting signals. Protein Eng 12:3-9.

Roskies AL, O'Leary DD (1994) Control of topographic retinal axon branching by inhibitory membrane-bound molecules. Science 265:799-803.

Schaeren-Wiemers N, Gerfin-Moser A (1993) A single protocol to detect transcripts of various types and expression levels in neural tissue and cultured cells: in situ hybridization using digoxigenin-labelled cRNA probes. Histochemistry 100:431-440.

Sharom FJ, Lehto MT (2002) Glycosylphosphatidylinositol-anchored proteins: structure, function, and cleavage by phosphatidylinositol-specific phospholipase C. Biochem Cell Biol 80:535-549.

Simon DK, O'Leary DD (1992) Development of topographic order in the mammalian retinocollicular projection. J Neurosci 12:1212-1232.

Sperry R (1963) Chemoaffinity in the orderly growth of nerve fiber patterns and connections. Proc Natl Acad Sci USA 50:703-710.

Tessier-Lavigne M, Goodman CS (1996) The molecular biology of axon guidance. Science 274:1123-1133.

Theiler K (1989) The house mouse: atlas of embryonic development. New York: Springer.

Walter J, Henke-Fahle S, Bonhoeffer F (1987) Avoidance of posterior tectal membranes by temporal retinal axons. Development 101:909-913.

Yu TW, Bargmann CI (2001) Dynamic regulation of axon guidance. Nat Neurosci 4 [Suppl]:1169-1176. 